\title{
The PIAAC Literacy Framework and Adult Reading Instruction
}

\author{
An Introduction for Adult Educators
}

Amy R. Trawick, CALLA

\begin{abstract}
:
This article is excerpted (with slight adaptations) from the reports Using the PIAAC Literacy Framework to Guide Instruction: An Introduction for Adult Educators (Trawick, 2017) and Bringing Reading Instruction to Life: Supplement to the Introductory Guide (Trawick, 2018). The Programme for the International Assessment of Adult Competencies (PIAAC) conducted an international literacy assessment for adults in 2012 and 2014, and this article describes how adult educators can use its literacy framework to frame instruction as well. Key aspects that can guide teaching and learning include a "literacy-in-use" orientation to reading, the definition for "literacy" adopted by the literacy expert group, and how PIAAC operationalized Context, Content, and Cognitive Strategies. A model of contextualized reading instruction is proposed as a way to organize reading instruction.
\end{abstract}

The Organization for Economic Co-operation and Development (OECD) has invested in international surveys throughout the years, with each assessment including rather detailed information about the skill levels of the adults in the United States.

The results of the literacy portion of the latest assessment, the Survey of Adult Skills, give one pause. Though the average score for adults in the United States is not significantly different from the international average in reading literacy (Rampey et al., 2016), the overall average conceals results of great concern:

- A larger percentage of U.S. adults scored in the very lowest levels for reading literacy, compared to the international cohort;
- U.S. adults with less than a high school diploma scored lower than their peers internationally;

- While only $9 \%$ of Whites in the U.S. scored at the lowest levels of proficiency, 33\% of Blacks and $40 \%$ of Hispanics performed at these levels;

- Roughly $75 \%$ of unemployed adults (age 16$65)$ in the U.S. have less than a high school credential as their highest education level, and a third of these perform at the lowest levels in reading literacy; and

- Adults with the lowest literacy scores were more likely to report a poor health status and more limited civic engagement (Rampey et al., 2016). 
This news of how the skills of adults in the United States compare with their peers across the globe comes at a time when the nation is challenged by international economic competition and by a variety of social and political stressors, both at home and on the world stage (Kirsch, Braun, Yamamoto, \& Sum, 2007). Individually, U.S. adults face a dynamic and complicated labor market, including ever-changing technology and new occupational structures that are biased towards skilled and educated workers. Furthermore, in their homes, at work, and in their communities, adults confront diverse and often conflicting sources of information, delivered through platforms unimaginable twenty years ago. The latest international assessment data suggest that it is imperative that adults develop the requisite skills to participate fully in society and for their society to participate successfully in the international arena. The OECD (2013b) argues, "Without the right skills, people are kept at the margins of society, technological progress does not translate into economic growth, and enterprises and countries can't compete in today's globally connected and increasingly complex world" (p. 26).

\section{An Invitation}

The Survey of Adult Skills (a.k.a., "PIAAC"; see EXHIBIT 1) does more than provide a measure of the skill levels in participating countries. It also provides tools that educators may find useful in helping adults build those skills. These tools work well with adult education content standards that are being used across the country. The College and Career-Readiness
Standards for Adult Education (Pimentel, 2013), along with comparable state versions, have been adopted in efforts to prepare adult learners in the United States for the skill demands of the $21^{\text {st }}$ century. These college and career readiness standards (CCRS) articulate the English language arts/literacy and mathematics skills required to succeed in three broad arenas: 1) entry-level positions of promising careers, 2) introductory academic college courses and workforce training programs to prepare for these careers, and 3) activities required of active citizens in a demanding democracy. For the first time, efforts are aligning $\mathrm{K}-12$, postsecondary education, and adult education in a vision for what it means to be "college and career ready."

These efforts were bolstered by the 2014 passage of

\section{EXHIBIT 1: Overview of PIAAC}

The Survey of Adult Skills, formally known as the Programme for the International Assessment of Adult Competencies, or PIAAC, is a cyclical, international assessment of the skill levels of adults in advanced, information-rich economies. Coordinated by the Organization for Economic Co-operation and Development (OECD), the PIAAC assessments have been conducted in three rounds internationally thus far (in 2012, 2014, and 2017).. The "key information-processing skills" of literacy (reading only), numeracy, and problem solving in technology-rich environments have each been assessed through separate surveys. These skills were selected because they were deemed "essential for full participation in the knowledge-based economies and societies of the 21st century" and:

- $\quad$ "necessary for fully integrating and participating in the labour market, education and training, and social and civic life;

- $\quad$ highly transferable, in that they are relevant to many social contexts and work situations; and

- 'learnable' and, therefore, subject to the influence of policy" (OECD, 2013a, p. 18).

For more information on PIAAC visit http://piaacgateway.com. 
the Workforce Innovation and Opportunity Act (WIOA; 2014), the principal legislation directing workforce and adult education activity nationally. Together, WIOA and the CCRS focus the field of adult education on developing skills with an eye towards college, careers, and citizenship. This emphasis has given rise to the need for approaches to teaching and learning that can realize this vision.

While the recent results of PIAAC (Rampey et al., 2016; OECD, 2013b) underscore the importance of this national activity, the work that went into developing the survey provides material that, with adaptation, has the potential to enhance the delivery of adult education itself. In particular, the conceptual framework that guided the literacy assessment (a.k.a. "the literacy framework") invites a way of thinking about adult reading instruction that is based on theory and research related to how adults use reading in their everyday $21^{\text {st }}$-century lives.

Central to the PIAAC work is an understanding that complex skills are best conceptualized in terms of how adults actually use the skills as they go about the various tasks that comprise their adult lives. In the case of reading, individuals draw from and put to use cognitive strategies and component sub-skills (e.g., alphabetics and vocabulary) as they tackle reading tasks throughout their day, but ultimately it is the accomplishment of the tasks themselves that matters most. What PIAAC is principally interested in assessing, regarding reading, is how well adults can apply key reading skills to accomplish these adult reading tasks-using adult-oriented materials, in authentic contexts, for real-life purposes. The term "literacy-in-use" captures this intent (PIAAC Literacy Expert Group, 2009, p. 6).

The reasoning and the conceptual tools that made such rich assessment work possible can do doubleduty in helping to prepare adults for these kinds of reading tasks. The National Research Council (NRC, 2012) notes that adult literacy instruction "is most likely to lead to durable, transferable learning if it incorporates real-world activities, tasks, and tools" (p. 6). The PIAAC literacy framework focuses on these "real world activities, tasks, and tools," and, thus, offers the field of adult education an opportunity to think in creative and sophisticated ways about adult literacy instruction. The purpose of this article is to explore how specific aspects of the PIAAC literacy framework might inform instructional planning and curriculum development in adult education, especially related to reading instruction.

\section{The Building Blocks of the PIAAC Literacy Framework}

To start, this section overviews some key pieces of the PIAAC literacy framework, ones that serve as building blocks for developing items for the survey. They include the definition of literacy and three basic elements comprising reading tasks: contexts, content, and cognitive strategies. Embedded in the discussion are applications for adult education.

\section{Definition for Literacy}

The literacy framework was developed by a literacy expert group and its members, and how they defined literacy for the Survey of Adult Skills sets the stage for everything else in the framework. The specific words in the definition provide valuable insight into what the international community valued about literacy for this iteration of the PIAAC assessments, but it also makes more concrete what can otherwise be a rather abstract concept. See EXHIBIT 2.

It is important to note upfront that the PIAAC framework uses literacy to refer to reading-related activity, as opposed to activity related to spoken 
language or writing. The survey focused only on reading because of the current limitations of assessing across language and culture on an international scale (OECD, 2013b; PIAAC Literacy Expert Group, 2009). Note, too, that the skills typically associated with reading are listed in the second sentence of the definition and range from decoding words to evaluating complex texts. The PIAAC framework states that literacy encompasses these skills; it is not defined as these skills'.

It is in the first sentence that we see the core of PIAAC's use-oriented definition of literacy. The definition identifies three major purposes for literacy: 1) participate in society, 2) achieve one's goals, and 3) develop one's knowledge and potential. The expert group explained that an earlier draft of the definition originally used the word "function"

\section{EXHIBIT 2: Defining Literacy}

PIAAC

\begin{abstract}
Literacy is defined as the ability to understand, evaluate, use and engage with written texts to participate in society, to achieve one's goals, and to develop one's knowledge and potential.
\end{abstract}

Literacy encompasses a range of skills from the decoding of written words and sentences to the comprehension, interpretation, and evaluation of complex texts. It does not, however, involve the production of text (writing).

Information on the skills of adults with low levels of proficiency is provided by an assessment of reading components that covers text vocabulary, sentence comprehension and passage fluency.

(OECD, 2013b, p. 59)

*PIAAC delineates literacy from numeracy and problem solving in technology-rich environments and defines each with its own framework. in the first purpose. The expert group ultimately landed on "participate" in order "to focus on a more active role for the individual" (PIAAC Literacy Expert Group, 2009, p. 9). Here's how the expert group explained the intent:

\section{Adults use text as a way to engage with their social} surroundings, to learn about and to actively contribute to life in their community, close to home and more broadly. And for many adults, literacy is essential to their participation in the labor force. In this, we recognise the social aspect of literacy, seeing it as part of the interactions between and among individuals. (PIAAC Literacy Expert Group, 2009, p. 9)

The definition goes on to underscore the role of text in the pursuit of personal goals and developing one's potential. Personal goals might range from managing a shopping trip to managing a career, from choosing a menu item to deciding upon a retirement plan, from negotiating the bureaucracy of the local school system on behalf of a child to navigating the financial aid waters of the local community college on behalf of oneself. Managing texts is likely required in all of these goal pursuits, especially in an information-rich society. Perhaps unsurprisingly, developing one's knowledge and potential through lifelong learning-whether that learning is formal and classroom-based, or informal and self-directed-often requires text as well.

A use-oriented view of adult literacy, then, must take into

\footnotetext{
${ }^{1}$ The literacy expert group addressed the role these skills play through a Reading Components assessment. Adults who were unable to successfully complete a set of four core literacy tasks at the start of the assessment were not required to complete the full literacy survey. Instead, they were directed to a Reading Components assessment that focused on three key reading components: reading vocabulary, sentence processing, and passage comprehension.
} 
consideration these three purposes for literacy. The four verbs we see in the PIAAC definition-understand, evaluate, use, engage--describe the types of interaction with text needed to achieve these purposes (see EXHIBIT 3).

Understand and evaluate are familiar constructs in adult reading education and are well represented in states' adult education content standards. The other two types of interactions, however, may warrant a moment of deliberation. The expert group described "using" a text as "applying the information and ideas in a text to an immediate task or goal or to reinforce or change beliefs" (PIAAC Literacy Expert Group, 2009, p. 13). Most questions in the PIAAC literacy assessment are framed within this use orientation, but how adults use written text is also addressed in the questions in the PIAAC Background Questionnaire that probe readingrelated activities at work and in everyday life. For instance, respondents were asked whether they read the following and to what extent:

- directions or instructions

- letters, memos, or e-mails

- $\quad$ articles in newspapers, magazines, or newsletters

- articles in professional journals, or scholarly publications

- books, fiction or nonfiction

- manuals or reference materials

- bills, invoices, bank statements, or other financial statements

- diagrams, maps or schematics

These uses of written text speak to an immediate interaction with text; reading engagement, however, "refer[s] to the degree of importance of reading to an individual and to the extent that reading plays a role in their daily life" (PIAAC Literacy Expert Group, 2009, p. 20). In other words, engagement addresses the general attitudes and behaviors related to reading, especially the
Types of Interaction with Text

Readers

- understand

- evaluate

- use

- $\quad$ engage with written text

\section{Purposes for Literacy}

- $\quad$ participate in society

- achieve one's goals

- develop one's

knowledge and

potential extent to which the individual views reading as a priority option for spending time and as a way of accomplishing goals. The expert group articulated five integrated aspects of engagement:

a. Amount and variety of reading. The more one reads and the more different types of reading (purposes, types of text) one uses, the greater one is engaged with reading.

b. Interest in reading. The more one seeks out reading as a means of obtaining information and for enjoyment, the greater one is engaged with reading.

c. Control. The more one feels in control of what one reads and is able to direct one's own reading, the greater the engagement.

d. Efficacy. The more an individual feels able to read well, especially the confidence to read successfully new texts, the greater one is engaged with reading. 
e. Social interaction. The more one is interested in sharing reading experiences and seeks out others to talk about reading, the more one is engaged with reading. (PIAAC Literacy Expert Group, 2009, p. 20)

Fostering reading engagement is an increasingly vital piece of the overall mission of many adult education programs, especially in light of the fact that some adult learners do not remain in those programs long enough to achieve the skill gains that could make a difference in their lives. Reder (2012) maintains that inviting students to develop their reading skills in the classroom through participation in reading practices that mirror those they find "in real life" (e.g., analyzing nutrition labels; finding and reading online information; reading, evaluating, and discussing opinions about current events) may inspire and enable students to engage in those practices when they depart the program. The hope is that, by continuing to interact with texts after their departure, students will reinforce and further develop their reading skills even without the benefit of ongoing instruction. That hope--and the multifaceted nature of the concept of engagement itself--suggest that these reading practices need to be taught and learned in adult education programs in ways that build self-efficacy, that promote ownership in the reading and learning processes, and that foster a sense of collaboration.

Taken as a whole, the purposes and types of text interaction described in PIAAC's definition for literacy offer the field a concrete reference point for reflecting on our vision for literacy (reading) instruction in our classroom and program settings. Do these purposes seem legitimate? Are these interactions with texts indeed the kinds we want to promote? If so, are we structuring learning opportunities in reading and wrap-around services for adult learners in ways that transfer to their lives? Practitioners in adult education programs might use this definition to revisit the program's mission/ vision statement, curriculum, and/or services to ascertain if the scope of literacy programming offered supports the purposes for literacy and types of text interaction described in the literacy framework. Answering questions like those posed in EXHIBIT 4 can aid in this kind of reflection, a first step to building the collaboration and system support required for the integrated instructional approaches that follow. 


\section{EXHIBIT 4: Guiding Questions for Reflecting on the PIAAC Definition for Literacy}

$\begin{array}{cc}\text { Description Questions to Ask } & \end{array}$

PURPOSES FOR LITERACY

Participate

in society

Refers to the active ways in which adults use text to interact with each other in order to contribute to their homes, communities, and workplaces.

Refers to how adults use text to address their

Achieve one's goals immediate and long-terms needs/goals. These goals may range from finding housing to progressing in a career to participating more fully in the community.

Develop Refers to how adults use text for self-directed, knowledge and potential informal, or formal learning to improve some aspect of their life.
1. For each purpose, answer these questions:

- In what ways does your program mission statement capture this purpose?

- In what ways does your CCRS document further this purpose? (In addition to the standards themselves, look at the Introduction, examples, guidelines, etc.)

- Where/how/to what degree do your program's curricula, materials, and/or approaches already foster this purpose? Find specific examples.

- (Teachers) Look through recent lesson plans. In what ways are you already teaching to this purpose?

2. What are the implications moving forward?

\section{TYPES OF INTERACTION WITH TEXT}

Addresses such things as understanding vocabulary, identifying the main idea, grasping the author's

To understand

To evaluate

To use

To engage purpose and how ideas are organized, including knowing how these are affected by social function. Many understanding tasks can be quite complex, requiring high-level inferencing and analysis.

Addresses whether a particular text is relevant for the task-and reliable as a source. It can also involve making judgments about the accuracy of a particular statement or the quality of an overall text. The ability to evaluate text has emerged as an important skill in the new digital age, where adults are inundated with information from sometimes questionable sources.

Addresses ability to apply information in a text to a specific goal. Adults don't read menus to define words or answer questions. They read menus to order food. They read directions to get something done. They read websites to find information that they can act on.

Addresses the degree to which adults seek out reading to obtain information or for enjoyment; the amount and range of reading they do; the confidence they have in their own reading and their ability to direct their own reading; and how likely they are to share their reading with others.
1. For each type of interaction, answer these questions:

- How is it captured in your program's mission statement? How might the mission statement be revised to better capture this interaction?

- How do the Reading CCRS prompt this interaction?

- Where/how/to what degree does this interaction already show up in your program's curricula, materials, and/or approaches?

- (Teachers) Review recent lesson plans. In what ways are you already teaching for this type of interaction?

2. What are the implications moving forward? 
Basic Task Elements: Contexts, Content, and Cognitive Strategies

After clearly defining literacy, the PIAAC literacy expert group next had to decide how to assess it. The PIAAC expert groups from across all three of its assessments developed a basic framework, one that was customized and elaborated upon to guide assessment in each specific skill domain. These elements (see EXHIBIT 5) describe essential aspects of authentic adult tasks in informationrich societies and can be used to guide teaching and learning for adult students.

Contexts. The first element of the basic PIAAC assessment framework is contexts, defined for all the PIAAC assessments as "the different situations in which adults have to read, display numerate behavior, and solve problems" (OECD, 2013b, p. 59). For literacy, "the circumstances and context in which reading takes place may influence the motivation to read and the manner in which texts are interpreted" (OECD, 2012, p. 22). That means that the PIAAC expert group needed to identify those key contexts in which adults operate and then to specify the texts and tasks appropriate within those contexts. Four broad contexts were identified for literacy use for adults:

- Work and occupation (e.g., job search, wages, salaries, benefits, being on the job)

\section{- Personal uses}

- Home and family (e.g., interpersonal relationships, personal finance, housing, and insurance)

- Health and safety (e.g., drugs and alcohol, disease prevention and treatment, safety and accident prevention, first aid, emergencies, and staying healthy)

\section{EXHIBIT 5: PIAAC Framework Elements}

\begin{tabular}{|c|c|c|}
\hline $\begin{array}{l}\text { Framework } \\
\text { Element }\end{array}$ & $\begin{array}{l}\text { General Definition } \\
\text { (applied across the assessments for literacy, numeracy, and } \\
\text { problem-solving in technology-rich environments) }\end{array}$ & Applied to Literacy \\
\hline Contexts & $\begin{array}{l}\text { The different situations in which adults have } \\
\text { to read, display numerate behavior, and solve } \\
\text { problems }\end{array}$ & $\begin{array}{ll}\text { - } & \text { Work-related } \\
\text { - } & \text { Personal } \\
\text { - } & \text { Society and community } \\
\text { - } & \text { Education and training }\end{array}$ \\
\hline Content & $\begin{array}{l}\text { The texts, artifacts, tools, knowledge, } \\
\text { representations and cognitive challenges } \\
\text { that constitute the corpus to which adults } \\
\text { must respond or use when they read, act } \\
\text { in a numerate way or solve problems in } \\
\text { technology-rich environments }\end{array}$ & $\begin{array}{l}\text { Different types of text. Texts are characterized by their } \\
\text { medium (print-based or digital) and by their format: } \\
\text { - Continuous or prose texts } \\
\text { - Non-continuous or document texts } \\
\text { - Mixed texts } \\
\text { - Multiple texts }\end{array}$ \\
\hline $\begin{array}{l}\text { Cognitive } \\
\text { Strategies }\end{array}$ & $\begin{array}{l}\text { The processes that adults must bring into } \\
\text { play to respond to or use given content in an } \\
\text { appropriate manner }\end{array}$ & $\begin{array}{l}\text { - } \text { Access and identify } \\
\text { - Integrate and interpret (relating parts of text to one } \\
\text { another) } \\
\text { - Evaluate and reflect }\end{array}$ \\
\hline
\end{tabular}

*Adapted from EXHIBIT 2.1 Summary of Assessment Domains in the Survey of Adult Skills (PIAAC) (OECD, 2013b, p. 59). 
- Consumer economics (e.g., credit and banking, savings, advertising, making purchases, and maintaining personal possessions)

- Leisure and recreation (e.g., travel, recreational activities, and restaurants, as well as material read for leisure and recreation itself)

- Society and community (e.g., public services, government, community groups and activities, and current events)

- Education and training (e.g., opportunities for further learning)

\section{How might practitioners apply this information?}

Let's look at how one teacher, Marco, might use the PIAAC literacy contexts in his work:

Marco teaches in a large urban community-based organization and has a class of 15 intermediate students (GLE 4-8.9). He is responsible for teaching to the state's College and Career Readiness (CCR) English Language Art (ELA) Standards and has been trained in STAR, a federally-sponsored approach to teaching adult intermediate readers. According to his program's mission, he is also supposed to simultaneously build students' content knowledge and support them in meeting their college, work, family, and life goals. Many students plan to move into the next class to prepare for the GED. Marco's class meets 5 hours a week for ELA instruction. Recently, Marco's local program used the PIAAC literacy framework to make a reference sheet to use when planning instruction for life-oriented reading.

Marco is ready to plan the context focus for his next unit. One of the students in the class has just been diagnosed with diabetes, and there has been a good deal of informal talk about what diabetes is, what causes it, and how she's going to treat it. Students have also been talking about gun violence. Marco needs to decide where he wants to focus the skill instruction for the unit. He looks over his list of PIAAC topics and realizes that the class has recently completed units in career exploration (work), what it takes to go to college (education and training), elections (society and community), and current events (society and community). He reads through the PIAAC options and sees the "health and safety" category under the "personal" section and realizes 1) addressing student health is a major part of the program's mission and 2) he hasn't covered science in whole class instruction yet. He knows he needs to be building students' background knowledge both for the GED and for life. The topic "disease prevention and treatment" is listed in the PIAAC content topics and is directly related to his students' expressed interests. Marco decides to proceed from the student interest in diabetes to frame a unit around students' own "health concerns," permitting students to research disease prevention and treatment if that is where their concern lies. The unit will enable them to build their knowledge related to their bodies and health and to develop their informational reading skills along the way.

Marco wants to expose learners to an array of contexts over time so they come to understand more fully the types of situations in which literacy is used and how literacy use varies across contexts. Teachers and curriculum developers would ideally draw a specific context directly from the students whenever possible to assure that students in the classroom see the immediate or future relevance of selected contexts. However, the PIAAC categories can serve as concrete reminders of potent "hot topics" for adults from which to start.

Content. The second element in the literacy framework, content, refers to the different types of texts adults read. PIAAC targets advanced, information-rich countries, so in identifying texts, the expert group was influenced by the role computer technologies play in accessing and presenting text. The top-down, left-right orientation of traditional print is augmented by the "nonlinear, recursive, and interactive nature" (PIAAC Literacy Expert Group, p. 5) of digital environments, complicating what it is that adults must know and manage to navigate text. The increased abundance of non-continuous textsin graphs, charts, bullet points-also requires a unique set of skills. Thus, texts used in the literacy assessment were described by their medium (print-based or digital) and format (continuous 
text, non-continuous text, mixed within one text, or multiple).

The expert group teased out further aspects of texts as well. EXHIBIT 6 shows additional differentiations: rhetorical stance, layout of noncontinuous texts, and digital text considerations. the rhetorical stances category. The topic will likely employ the use of tables to convey information, so Marco thinks it is a good opportunity to provide instruction in reading and constructing tables (intersected lists). Because students will also be working on websites, he decides to provide instruction and practice with index-like links to help them go right to the specific information they need.

\section{EXHIBIT 6: Features of Authentic Texts}

Rhetorical
(for Continuous and Non-
- Description
- Narration
- Exposition
- Argumentation
- Instruction
- Records

Let's pick up with Marco to see how he makes use of this information.

Marco has decided to frame a unit around health concerns, so he begins to think about the kinds of texts students will read. His program uses an intake form to ascertain what kinds of texts students want to learn how to read. He reviews those results for the students in his class. Most students have indicated they want to learn how to read websites more efficiently, which is a natural fit with the context of health concerns. Adults often research their health issues on the Internet. He envisions students conducting a structured investigation about a health concern of their choice and presenting their findings through a class blog in which they share the causes and impacts of their health issue and how they are changed by what they found. Right now he thinks students will read two texts, one of which will be an Internet article (digital) they find.

Marco then refers to the features of authentic text from PIAAC, keeping in mind the context of the readings students will be involved with as they explore their health concerns, as well as students' past experiences with reading. In reading about their health concerns, students will naturally encounter a great deal of exposition, so Marco decides to make that the focus from
For Marco, the PIAAC categories and descriptions provide a way to consider authentic types of texts adults need to experience in the classroom in order to be prepared for the often complex literacy tasks they will increasingly encounter in their homes, their workplaces, and their communities. He wants to ensure that students are taught the social functions, formats, and skills related to common rhetorical stances. He also wants to provide practice in the various kinds of noncontinuous texts. Finally, he wants to make sure students themselves are actively maneuvering through digital texts, learning what to ignore and what to target to find the information they need. Marco does not always include all three content categories in one unit; however, he does think carefully about them as he designs learning experiences for his class.

Cognitive strategies. The third basic element in the PIAAC framework is cognitive strategies, 
those "processes that adults must bring into play to respond to or use given content in an appropriate manner" (OECD, 2013b, p. 59). Three main sets of cognitive strategies were targeted in the literacy assessment: 1) access and identify; 2) integrate and interpret (relating parts of text to one another); and 3) evaluate and reflect. While other cognitive strategies may be relevant for any particular real-life task, these three were deemed sufficiently prominent in importance to be assessed on the last three international assessments.

- Access and identify. The first set of cognitive strategies-access and identify-refers to finding information in a text, a common need of adult readers. Sometimes this can be a rather straightforward exercise, identifying a single piece of literal information that is "right there," such as a phone number or a date. However, sometimes tasks of this type can be challenging. They might involve making inferences and/or drawing upon understanding of formats and the social functions of texts, knowing, for instance, how authors tend to organize arguments or how webmasters tend to organize websites. Thus, these questions are not necessarily easy. The expert group identified two sub-types of access and identify strategies: locating refers to finding just one piece of information, and cycling refers to finding multiple pieces of information.

\section{- Integrate and interpret (relating parts of} text to one another). Another major aspect of what adults do when they read is to connect different parts of text. Readers may need to understand how the end of a text relates to its beginning, how an anecdote supports an argument, how a graph illustrates findings from a research study. A major part of the PIAAC literacy assessment, then, targets the cognitive strategy integrate and interpret. To integrate and interpret is to determine the relationship between different parts of a text, whether that relationship is explicitly stated or not. Common relationships include problemsolution, cause-effect, category-example, equivalency, compare-contrast, and wholepart (e.g., determining the purpose of a text or its main theme).

- Evaluate and reflect. The ubiquity of text in today's world requires adult readers to separate the relevant from the irrelevant, the reliable from the unreliable. Online texts may be posted by anyone, regardless of his or her credentials or expertise, and may be left online long after the timeliness of the content has passed. The third PIAAC cognitive strategy, evaluate and reflect, addresses the often difficult process of determining the quality of information, taking into consideration that readers often employ information, ideas, or values beyond the text to decide its relevance and credibility for an issue at hand. Readers may also need to attend to such factors as a text's purposefulness, register, structure, accuracy, timeliness, and use of evidence and language.

Here's how PIAAC's description of cognitive strategies might inform Marco's planning:

Marco thinks about the type of texts students will encounter as they read about health concerns in the unit, what they need to learn to read those texts, and what he is responsible for teaching students at this level. He has decided to focus instruction on exposition (rhetorical stance), tables (noncontinuous text format), and text-embedded links. Now he ponders the cognitive strategies he needs to teach. Since students will be looking for specific kinds of information about their health concerns and will be navigating websites, Marco knows he will need to provide instruction in access and identify, specifically in locating information using index-link links, headings, and key words related to causes/risks. Another focus will need to be integrate and interpret, notably cause 
and effect, since health concerns are often discussed in terms of prevention/causes and treatment. He has traditionally thought of cause and effect as text structure ${ }^{2}$, and he can think of ways to bring in graphic organizers to help students analyze the expository text they are reading. Since students will be researching health concerns on the Internet (even with restricted websites), Marco feels he should also teach them some basics about evaluate and reflect, such as assessing the credibility of the source.

Let's take note of a few aspects of Marco's planning. First, Marco is using a unit structurelinked lessons related to the same topic--to plan instruction. That means students will be reading multiple texts over time, with ample opportunities for Marco to teach and for students to practice and integrate several strategies within one unit. Identifying specific strategies (e.g., locating information using index-link links, headings, key words, identifying cause and effect; evaluating credibility of sources) within each cognitive strategies category enables him to proceed in his planning with clarity of intent. Exploring a health concern utilizes a great many skills/strategies, but Marco cannot teach them all to students with the same intensity. He must use the time he has with students in a focused manner. Thus, he targets just a few strategies so he can provide the intensity of explicit instruction plus practice needed for students to learn them well.

Secondly, Marco does not need to select strategies from across all three PIAAC sets of cognitive strategies. He does so in this case because it makes sense for what the real-world task asks of students-and he thinks he can focus the instruction appropriately to provide enough practice in each strategy. In many units, however, teachers may draw from only one or two of the PIAAC sets of cognitive strategies.
Thirdly, Marco need not limit his strategy selection to just the three sets of cognitive strategies identified in the literacy framework at all. The PIAAC literacy expert group restricted the assessment to these broad sets of highly relevant strategies for the purposes of the international survey; however, there are other skills and strategies that students may need to learn in order to accomplish a wide range of tasks. Practitioners should feel free to incorporate other skills and strategies into instruction as required by the tasks students are attempting, the content standards teachers are required to teach, and the reading components (e.g., phonics, vocabulary) students need to develop. The inclusion of the cognitive strategies in the PIAAC framework helps us remember, though, that 1) adults use strategies/ skills in the pursuit of real-world reading tasks (and that's, ultimately, how we should teach them) and 2) the three identified sets have high-utility in adult reading activity.

\section{Model for Contextualized Reading Instruction}

The use-oriented conception of competency that underlies the PIAAC literacy definition and framework is congruent with research on transfer of learning. In general, this body of literature points to the increased likelihood that transfer of learning is enhanced either when there is a considerable overlap between the features of a task in a learning situation and a new task or when a skill is learned and practiced in multiple contexts (NRC, 2012: Perin, 2011).

Since one of our goals in adult education is to help adults build competency in using literacy skills to accomplish real-life goals and purposes, it

\footnotetext{
${ }^{2}$ Text structure refers to common patterns authors use to organize ideas within a written text. For more information, see http://www.adlit. org/strategies/23336.
} 
makes sense that we would want to construct in-class reading activities that mirror these reallife reading activities. The key elements of the PIAAC framework-contexts, content (texts), and cognitive strategies-all contribute to thinking about and constructing these authentic reading activities for instructional purposes.

It might be helpful to think about these basic elements as being nested within one another, and to change the language a little bit as we move more fully from the PIAAC framework into instructional planning (see EXHIBIT 7). Let's use the word "skills" to refer not only to PIAAC's cognitive strategies but also the reading components (e.g., phonics, fluency) and other skills articulated by a state's College and Career Readiness Standards. The PIAAC work helps us envision how these skills are used in real-life, as we read text(s) in the pursuit of an overarching task, situated within an authentic adult context. By applying this same organizing principle of nesting and contextualizing to construct learning activities, we can provide students with meaningful learning experiences that develop literacy-in-use for long-term retention and transfer.

As we saw with Marco's example, this kind of instruction entails teaching in a unit. Identifying a literacy task for a unit, one that is central to the unit and demonstrates in essential ways how literacy is used in "real life," is crucial. Such a task is considered authentic. Since many students will be moving on to postsecondary and training settings, literacy tasks that replicate or simulate the kinds of reading they'll experience in these contexts can also be considered authentic, if the transfer to those settings is made clear. The goal is to design an overarching literacy task that is as authentic as possible, considering the limitations of such things as time, materials, and transportation. We can think about the task in this model as a culminating activity that requires the learner to practice and ultimately use targeted reading skills, either to do something (e.g., find contact information; shop for groceries) or to access, analyze, and evaluate information in order to produce a product (e.g., a piece of writing or an oral presentation). Ideally, the culminating activity will also have an audience other than the teacher, such as the students themselves (as with a journal), classmates, the larger program/adult learning center, the workplace, or the community.

\section{EXHIBIT 7: Model for Contextualized Reading Instruction}

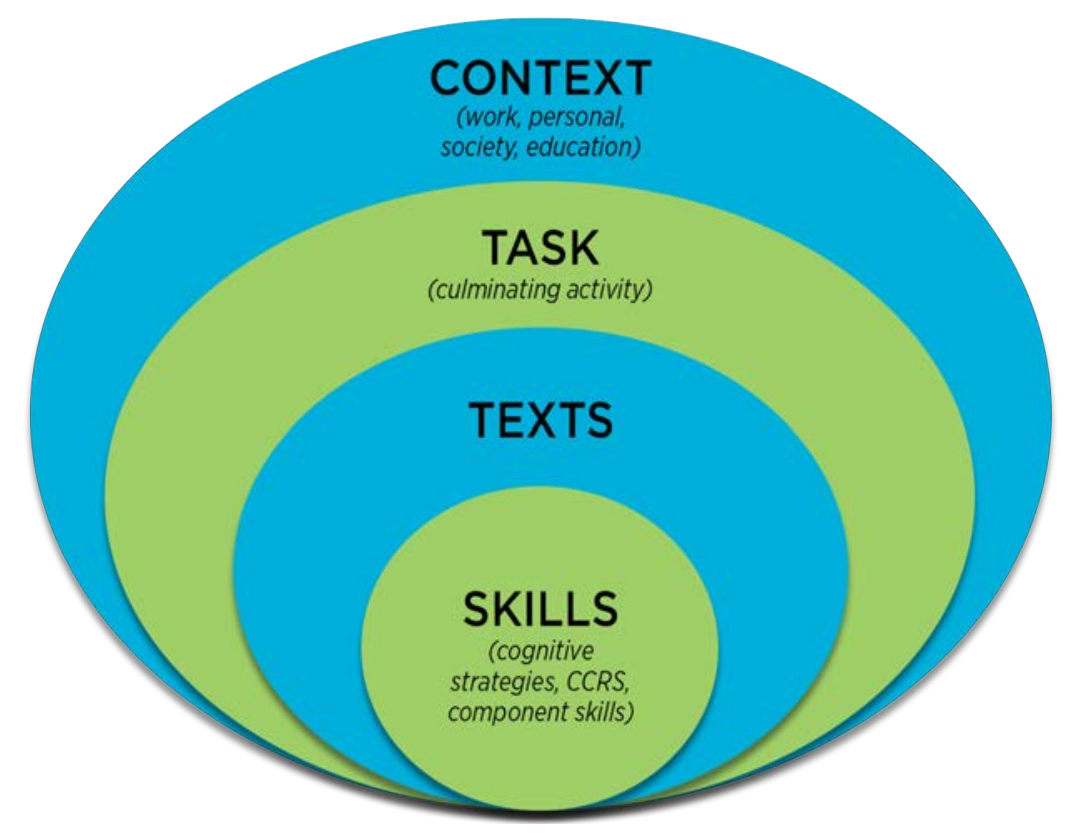


There are a number of ways to arrive at a culminating task that can frame instruction. Two options are described below: Option 1 shows how a teacher starts with a task and identifies the relevant skill required to complete the task. Option 2 reverses the process, with the teacher beginning with a targeted skill and contemplating an authentic reading tasks that applies that skill.

Whether Option 1 or Option 2 is used, identifying both the task and the targeted skill(s) happens early in the instructional design process. Soon afterwards, the teacher can plan lessons that will get students to those outcomes. This kind of design is often referred to as backward design

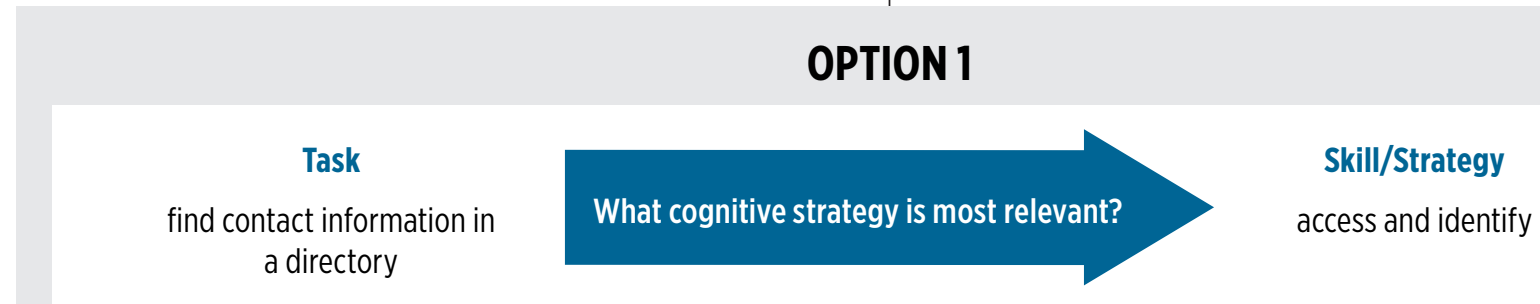

\section{OPTION 2}

Skill/Strategy

access and identify

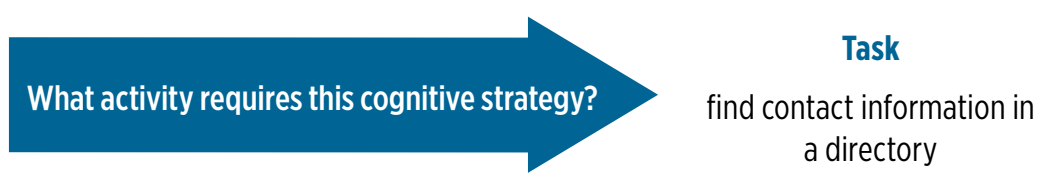

\section{EXHIBIT 8: Sampling of Contextualized Units}

TOPic FINDING CONTACT INFORMATION

(low level)

\section{Context}

Task

Community, Work

Find contact information in a simple directory

Texts Print-based, digital

Non-continuous

Records

(Simple/simplified online, print directories)

Skills Access and identify; $A B C$ order; scanning; specific sound-symbol correspondences; etc.
CAREER EXPLORATION

(intermediate level)

Work

Compare 3 careers and identify the best fit; explain why it's the best fit

Print-based, digital

Continuous; non-continuous

Exposition

(Online and print career resource materials--e.g., O*NET)

Compare and contrast; tables; graphs; text-embedded links
RESEARCHING TOPICS THAT MATTER

(high level)

Education and training, Community

Write a letter to an online community discussion board discussing multiple sides of a controversial topic currently in the news (e.g., GMOs, global climate change), making the case for one particular side

Print-based, digital

Continuous; non-continuous

Argumentation, Exposition

(Student-accessed print and online texts)

Evaluate and reflect-credibility of sources; argumentation; access and identify-finding diverse sources; 
(Wiggins \& McTighe, 2006). EXHIBIT 8 provides examples of what contextualized units might look like in classrooms at different levels when constructed around these basic unit features.

To ensure that these contextualized units do the work intended, practitioners can use the questions in EXHIBIT 9 as a guide. and features. The proficiency with which adults are able to navigate these texts for a range of purposes has implications not only for themselves and their families, but for their workplaces, their communities, and for the larger society. Our challenge as a field is to continue to find ways to help adult learners increase their reading proficiency, meeting adult learners where they are

\section{EXHIBIT 9: Guiding Questions for Designing Contextualized Units}

\begin{tabular}{|c|c|}
\hline Feature & Questions to Ask \\
\hline Context & $\begin{array}{l}\text { - Is the context important to students, either now or in the future? How do you know? } \\
\text { - Has there been variety in the contexts covered in previous instruction? If not, is that okay? How do you } \\
\text { know? } \\
\text { - What do learners already know about the context/topic? }\end{array}$ \\
\hline Task & $\begin{array}{l}\text { - How will students demonstrate their learning of the targeted understandings and skills in a way that is } \\
\text { most authentic to the context? (Is the purpose as "real" as possible? Is the audience as "real" as possible? } \\
\text { Is the product as "real" as possible?) } \\
\text { - Is the task appropriate for the level of the students? }\end{array}$ \\
\hline Texts & $\begin{array}{l}\text { - Will students read print-based or digital texts? Are students being exposed to a both as they progress } \\
\text { through units? } \\
\text { - Are students reading continuous or non-continuous texts? Are students being exposed to both as they } \\
\text { progress through units? } \\
\text { - Are students engaging with a variety of rhetorical stances and non-continuous text layouts across the } \\
\text { units? Is direct instruction being provided in these? }\end{array}$ \\
\hline Skills & $\begin{array}{l}\text { Which set(s) of cognitive strategies should be the focal point of instruction (considering level of students)? } \\
\text { - } \quad \text { Access and identify } \\
\text { - Integrate and interpret [problem-solution, cause-effect, category-example, equivalency, compare- } \\
\text { contrast, whole-part (e.g., main idea/details, purpose)] } \\
\text { - } \quad \text { Evaluate and reflect } \\
\text { - } \quad \text { Other } \\
\text { Do other reading skills/standards need to be taught, especially vocabulary, comprehension strategies, and } \\
\text { other essential components (phonemic awareness/phonics, fluency)? }\end{array}$ \\
\hline
\end{tabular}

\section{Conclusion}

The PIAAC definition for literacy is one that prioritizes the desire of adults to participate in society, to achieve their own goals, and to pursue lifelong learning. These purposes require adults to be able to understand, evaluate, use, and engage with texts that vary in rhetoric, formats, and connecting learning with what they want to be able to do. Oriented in authentic adult practice, PIAAC offers us a rich set of tools to do just that.

More ideas for using PIAAC's literacy assessment framework to inform adult education practice can be found in Using the PIAAC Literacy Framework to Guide Instruction: An Introduction for Adult Educators (Trawick, 2017) and Bringing Reading to Life: Supplement to the Introductory Guide (Trawick, 2018). 


\section{References}

Kirsch, I., Braun, H., Yamamoto, K., \& Sum, A. (2007). America's perfect storm: Three forces changing our nation's future. Princeton, NJ: Educational Testing Service.

National Research Council (2012). Improving adult literacy instruction: Developing reading and writing. Washington, DC: The National Academies Press, 2012. http://www.nap.edu/catalog/13468/improving-adultliteracy-instruction-developing-reading-and-writing

Organisation for Economic Co-operation and Development (OECD). (2012). Literacy, numeracy and problem solving in technology-rich environments:

Framework for the OECD Survey of Adult Skills. Paris, France: OECD Publishing. http://dx.doi. org/10.1787/9789264128859-en

Organisation for Economic Co-operation and Development (OECD). (2013a). The survey of adult skills: Reader's companion. Paris, France: OECD Publishing. http:// dx.doi.org/10.1787/9789264204027-en

Organisation for Economic Co-operation and Development (OECD). (2013b). The OECD skills outlook 2013: First results from the Survey of Adult Skills. Paris, France: OECD Publishing.

Perin, D. (2011). Facilitating student learning through contextualization: A review of evidence. Community College Review, 39(3), 268-295..

PIAAC conceptual framework of the background questionnaire main survey (2011). Paris, France: OECD Publishing.

PIAAC Literacy Expert Group (2009). PIAAC literacy: A conceptual framework (OECD Education Working Paper \#34). Paris, France: OECD Publishing.

"PIAAC: What the Data Say About the Skills of U.S. Adults" (n.d.). Available at http://static1.squarespace. com/static/51bb74b8e4b0139570ddf020/t/5 36a7917e4b058f6a3b2c6cf/1399486743068/ PIAAC+Results+Summary_ver508_050614.pdf
Pimentel, S. (2013). The college and career-readiness standards in adult education. Washington, DC: Office of College, Technical and Adult Education.

Rampey, B. D., Finnegan, R., Goodman, M., Mohadjer, L., Krenzke, T., Hogan, J., \& Provasnik, S. (2016). Skills of U.S. unemployed, young, and older adults in sharper focus: Results from the Program for the International Assessment of Adult Competencies (PIAAC) 2012/2014: First look (NCES 2016-039rev). Washington, DC: U.S. Department of Education, National Center for Education Statistics. Available at http://nces.ed.gov/ pubsearch

Reder, S. (2012). The longitudinal study of adult learning: Challenging assumptions (Research Brief: Perspectives on Literacy and Essential Skills). Montreal, QC: Centre for Literacy of Quebec. Available at http:// www.centreforliteracy.qc.ca/sites/default/files/ CFLRsrchBrief_Chllngng_Assmptns.pdf

Trawick, A. R. (2018). Bringing reading instruction to life: Supplement to the Introductory Guide. Washington, DC: AIR. Available at http://piaacgateway.com/ research-to-practice-guides

Trawick, A. R. (2017). Using the PIAAC literacy framework to guide instruction: An introduction for adult educators. Washington, DC: AIR. Available at http:// piaacgateway.com/research-to-practice-guides

Wiggins, G., \& McTighe, J. (2006). Understanding by design (2nd ed.). Upper Saddle River, NJ: Pearson Education, Inc.

Workforce Innovation and Opportunity Act H.R. 803 (2014). Information available at http://www2.ed.gov/about/ offices/list/ovae/pi/AdultEd/wioa-reauthorization.html\#1 